\title{
O Ensino de História Regional nos Anos Iniciais da Educação Básica
}

\author{
Elison Antonio PAIM ${ }^{l}$ \\ Jussara Odete CORREA ${ }^{2}$
}

\section{RESUMO}

As reflexões expressas neste artigo são originárias de pesquisa realizada com professores de anos iniciais do Ensino Fundamental da rede pública municipal e estadual no município de Caxambu do Sul - SC. Buscamos como ocorre o ensino de história, especialmente os temas locais e regionais. Inicialmente, fazemos algumas considerações sobre o ensino de história regional, bem como, expressamos o que entendemos por região. Num segundo momento, apresentamos o grupo de professoras entrevistadas e como elas trabalham com história em suas aulas.

Pallavias-chave: Ensino de História - História Regional - Educação Básica.

\section{Considerações iniciais}

0 presente artigo é fruto de uma pesquisa para conclusão de curso de Especialização em Fundamentos da Educação. Os sujeitos da pesquisa são professoras da Rede Pública Municipal e Estadual de Ensino no Município de Caxambu do Sul - SC . Através de depoimentos orais gravados, levantamos dados sobre a formação profissional, as condições de trabalho, metodologia, planejamento, avaliação e mais especificamente sobre as questões regionais no ensino de História.

\footnotetext{
I Ioutor em Kiducação pela Unicamp; Mestre em História pela PUC - São Paulo; Professor do curso de História e Coordenador do Centro de Memória do Oeste de Santa Catarina - CEOM, ambos vinculados a Universidade Comunitária da Região de Chapecó- UNOCHAPECÓ. E-mail: elisonpaim@hotmail.com.

Craduada em História, Especialista em Fundamentos da Educação pela UNOESC-Chapecó, Professora da Rede Pública Estadual de Santa Catarina e da Rede Municipal de ensino de Caxambu do Sul. E-mail: jussiraodetec@yahoo.com.br:

Caxambu do Sul foi desmenubrado de Chapecó e emancipado em 14 de dezembro de 1962; localizado na Região ()este do listado de Santa Catarina dista aproximadamente $38 \mathrm{~km}$ de Chapecó. Possuí uma população aproximada a 5.000) hábitantes e apesar de diversificação da produção, tem como base econômica, a agricultura familiar:
} 
Como ponto de partida, optou-se em levantar dados de identificação, formação profissional, tempo de serviço, situação funcional, carga horária e piso salarial, uma vez que não podemos dissociar a vida profissional da vida particular de uma pessoa, pois, está inserida num meio social que envolve múltiplas relações em que tudo está imbricado, entrelaçado ao seu cotidiano (NóVOA, 1991; 1992).

Verificamos que o quadro do magistério público municipal de Caxambu do Sul atende exclusivamente os anos iniciais do Ensino Fundamental é formado apenas por profissionais do sexo feminino. É um perfil de mulheres polivalentes, possuem uma tripla jornada de trabalho, uma vez que, além de serem trabalhadoras do mercado formal em período integral ou semi-integral, complementam ou ampliam sua carga horária com atividades que as desconsideram como trabalhadoras - as tarefas domésticas e algumas que moram em comunidades rurais também trabalham na roça.

$\Lambda$ formação de $1^{\circ}$ grau de praticamente todas essas professoras ocorreu na década de 1970, período em que era proibida qualquer discussão que contestasse a ordem vigente e, o ensino era baseado num repasse de informações. 0 Ensino Médio profissionalizante também aconteceu com o objetivo de preparar o trabalhador para a indústria ou um professor repassador de conhecimentos, no caso do curso de Magistério.

As depoentes ingressaram na profissão antes mesmo de possuírem a habilitação legal, geralmente moravam em comunidades rurais em que logo que acabaram o primeiro grau já foram convidadas a ser professoras. Posteriormente, devido à exigência legal buscaram a habilitação para o magistério. Na impossibilidade de freqüentar um curso no ensino regular, restou uma alternativa, a modalidade à distância através do Projeto Logos II $^{4}$.

Ao analisarmos algumas histórias de municípios escritas no Oeste de Santa Catarina e dois livros sobre Caxambu do Sul, observamos que a preocupação

\footnotetext{
Este curso foi oferecido pela Secretaria de Estado da Educação de SC durante as décadas de 1970 e 1980. A coordenaçĩo e execução local ficavam a cargo da $1 l^{a}$ Unidade de Coordenadoria Regional de Ensino - UCRE, com sede em chanecóo. (o objetivo era a formação de professores em exercício da docência sem habilitação. Os professores participantes deslocavam-se de seus municípios para Chapecó onde aconteciam algumas aulas, geralmente en meses de férias escolares. Após o período de aulas os professores retornavam com uma série de materiais para estudo e resolução de exercícios modulares. Quando retornassem na próxima etapa deveriam realizar provis das diferentes disciplinas, caso aprovados eliminavam as disciplinas até a integraalização do curso de magistério.
} 
centra-se na cronologia, na descrição dos fatos, ṇa forma supostamente ordeira e harmônica como a sociedade foi se constituindo. Evidenciando-se assim elementos de uma história com descrição de dados geográficos e históricos calcadas no mito dos colonizadores pioneiros.

Buscamos junto às professoras do primeiro ao quarto ano como as questões regionais chegam ou não a salas de aula. Para desencadear o processo deste estudo, utilizamos uma perspectiva de história social que nos permitisse trazer a tona os sujeitos inseridos no contexto histórico vivido. Para tal nos valemos dos procedimentos da história oral que na concepção de Alessandro Portelli:

Entrevistas, sempre revelam eventos desconhecidos ou aspectos desconhecidos de eventos conhecidos: elas sempre lançam nova luz sobre áreas exploradas da vida diária das classes não hegemônicas [...] o único e precioso elemento que as fontes orais têm sobre $\mathrm{o}$ historiador, e que nenhuma outra fonte possui em medida igual, é a subjetividade do expositor [...] Fontes orais contam-nos não apenas o que 0 povo fez, mas o que queria fazer o que acreditava estar fazendo e o que agora pensa que fez (1997, p.31).

Para uma compreensão das questões regionais, dialogamos com autores que trabalham com história regional como Matoso (1998), Amado (1990), Galzerani (1996), e Paim (2003), Fuckner (1998) e Côgo (1999).

\section{Região}

Nabusca pelo trabalho com História Regional no Ensino Fundamental do $1^{\circ}$ a $4^{\circ}$ ano, evidencia-se a amplitude da discussão, nos remetendo às contribuições de vários historiadores como Martins (1990, p.55), nos mostra que o fenômeno região obedece a uma formulação teórica específica e, que, apenas existe como tal durante o período de predomínio de uma economia voltada para fora, e que se desintegra com o desenvolvimento interno da economia de mercado, principalmente no estágio monopolista.

Quem nos dá uma base para pensarmos uma história regional éEdward Palmer'Thompson (1981, p.57), quando afirma que o objetivo da história é "reconstruir, explicar e compreender seu objeto: a história real". Nessa lógica, a história regional 
seria uma forma de aproximar os est udos do vivido pelo aluno ou seus familiares. Ou ainda, conforme Marcon (1996) uma história regional faz emergir os conflitos e tensões concretas vividas cotidianamente, trazendo à tona as experiências dos grupos dominados e dos projetos que foram destruídos pelos dominantes.

Durante muito tempo uma perspectiva naturalista de região norteou 0 pensamento sobre a questão. 0 pensamento unificou-se em torno de princípios pré-determinados e entendidos como comuns, construiu-se um discurso de igualdade, considerado necessário ao progresso e desenvolvimento. Por outro lado, este discurso sufocou a tentativa de resistência, ou seja, as diferenças, as contradições e lutas de classes. Esse mecanismo foi utilizado com uma perspectiva de unificação, de integração de uma determinada região ao Estado como um todo homogêneo. Porém, nos últimos tempos esta forma de entendimento perdeu espaço, a partir de então, a preocupação centrou-se muito mais no homem, do que nos espaços naturais, como nos mostram Flores e Serpa:

Na delimitação de fronteiras, a língua, o habitat, a realidade social, tanto quanto as classificações mais naturais, apoiam-se em traços que, não tem nada de natural, sendo em ampla medida, o produto de uma imposição arbitrária, quer dizer, de um estado anterior de relação de forças no campo de lutas pela delimitação legítima. A fronteira, este produto de um ato jurídico e diplomático de delimitação, tanto produz a diferença cultural quanto ela é produzida (1999, p. 217).

Evidencia-se que para além da natureza há outros elementos componentes de uma região. Esta delimitação depende do homem, que a cria, a delimita e a define segundo seus interesses. Assim, a questão regional no mundo contemporâneo pode aparecer de diferentes formas, podendo mostrar a situação das minorias nacionais, traduzindo a questão social das áreas mais pobres.

\section{Ensino de histónia regional}

Os Parâmetros Curriculares Nacionais - PCNs, que apesar de todas as restrições a eles dirigidas, expressam contribuições para pensarmos uma história centrada nas questões regionais ao sugerir que o ensino de história deve destacar as temáticas regionais, pois: 
o aluno pode apreender a realidade na sua diversidade e nas múltiplas dimensões temporais. Destacam os compromissos e as atitudes dos indivíduos, de grupos e de povos na construção e na reconstrução das sociedades, propondo estudos de questões locais, regionais, nacionais, as mudanças e permanências de modo de viver, de pensar, de fazer e das heranças legadas por gerações (PARÂMETROS CURRICULARES NACIONAIS, 1998, p. 60).

Em Santa Catarina esta em vigor uma Proposta Curricular da Secretaria Estadual da Educação para todos os componentes curriculares. Para o ensino de História propõe "um redimensionamento radical, na abordagem eurocêntrica e colonizada desta dimensão. Deste modo consideramos que as abordagens da história européia e mundial devam ser referidas para possibilitar o entendimento das relações Brasil e América no mundo e não o inverso" (1998, p.165).

$\mathrm{Na}$ defesa da necessidade de produzirmos e ensinarmos conhecimentos regionais, Priori defende que devemos acabar com aquela história homogênea, unificadora, construtora de uma memória única para todo o Brasil, como se este fosse isento de diferenças,

entre regiões, entre estados e, inclusive, as diferenças entre regiões dentro do mesmo estado devem ser ressaltadas e estudadas. É claro que não se pretende aqui acabar com a construção de uma identidade nacional. Pelo contrario, qualquer projeto de resgate e de compreensão da memória nacional tem que considerar as diferenças regionais e locais (1999, p. 608).

Assim, o que se quer é justamente enfatizar as diferenças regionais, mostrando e valorizando não o que é genérico e sim o que é próprio, peculiar de cada local, possibilitando virem a tona os diferentes sujeitos com suas experiências, seus valores, crenças, seu modo de vida, enfim, com sua cultura. Ao trabalharmos dessa forma a história estaria sendo adotada como um "princípio metodológico capaz de aproximar o aluno de seu cotidiano, da sua família, dos conhecidos, enfim, da sua comunidade, pela possibilidade de identificação das características do processo histórico particular da comunidade"(MACHADO, 1999, p.214).

Ao estudarmos as questões regionais, é preciso considerar a dimensão temporal, a qual teria papel decisivo na construção de uma "pedagogia da memória que 
faça frente aos problemas de desenraizamento, falta de identidade e pluralidade cultural e rácica que caracterizam as nossas escolas" (MANIQUE; PROENÇA, 1994, p.21). Por outro lado, destacamos ainda que, o regional precisa ser

[...] em vez de um ponto de partida geográfico/regional/nacional (espacial) um ponto de chegada, a compreensão da responsabilidade pessoal com os demais e, com o meio ambiente em que todos vivem a vida como valor máximo, e aí a compreensão clara da defesa dos direitos humanos, a democracia como valor universal (CERRI, 1996, p.718).

Dessa forma, ao tomar a decisão de trabalhar com o teoricamente próximo, este há que ser considerado como ponto de partida para um contexto mais amplo, fazendo pontes, ligações, estabelecendo semelhanças, diferenças entre diferentes espaços, acontecimentos e temporalidades.

Os Parâmetros Curriculares Nacionais (1998) estão constituídos a partir da história do cotidiano que por sua vez esta integrada a um contexto mais amplo, incluindo os conteúdos históricos, pois:

[...] esta proposta opta por trabalhar com temas relacionados às questões urbanas, mas estabelecendo as articulações constantes com as questões rurais locais ou nacionais, mediante cada situação. 0 estudo dos problemas urbanos, na contemporaneidade, orienta, assim, a possibilidade de escolhas de grandes eixos temáticos sobre as questões locais, inserindo-as en dimensões espaciais de maior grandeza e dimensões temporais amplas, que abarcam a possibilidade de diálogos múltiplos entre o presente e o passado (p. 44-45).

Os conteúdos de História, assim como os demais, estão definidos por ciclos. 0 estudo no primeiro ciclo tem como eixo temático: História Local e do Cotidiano, priorizando estudos comparativos que permitem estabelecer semelhanças e diferenças - permanências e reelaborações culturais, partindo da família, da comunidade local com um olhar ampliado através da pesquisa. Nesta definição, acrescenta ainda como necessário:

[...] de que se ampliem estudos sobre o viver de outros grupos da sua localidade 
no presente, identificando as semelhanças existentes entre grupos sociais e seus costumes e, desenvolvam estudos sobre o passado e a localidade identificando as mudanças e as permanências nos hábitos, nas relações de trabalho, nas organizações familiares e educacionais urbana ou rurais em que convivem, etc.

\section{A região na sala de aula}

Trazendo a problemática regional para a sala de aula através da fala das professoras depoentes evidenciam-se as dificuldades que as professoras dos anos iniciais do Ensino Fundamental possuem em trabalhar, como nos revelou a professora Gicela:

[...] acho que não só a regional, mas a local a gente também encontra dificuldade de trabalhar, porque como a gente não lê sobre a história da gente, tem essa dificuldade. Mas, se a gente quiser se pode ter, é só buscar [...] É isso que... tem que fazer. Eu sei... Eu sei sim, que está faltando. Tenho buscado pouco, mas eu acredito que agora com mais tempo.

Evidencia-se o pouco conhecimento e a dificuldade da professora em trabaIhar com as questões regionais e história de sua comunidade. Assim, entendemos um pouco das dificuldades ao trabalhar temáticas regionais, pois, muitas vezes, nem mesmo os profissionais graduados em História possuem estes conhecimentos. Não queremos com esta afirmação apontar culpados ou culpabilizar as professoras. 0 que pretendemos é destacar a fragilidade da formação inicial das professoras dos anos iniciais quanto aos conteúdos das disciplinas específicas como é o caso da História. Outro elemento interessante que merece destaque é que boa parte delas no momento da pesquisa ainda possuíam como formação apenas o curso de Magistério a nível médio.

Por outro lado, há pequenos sinais de um estudo da realidade mais próxima, quando, as professoras buscam algumas fontes locais como objeto de estudo, como nos mostra esta outra profissional "Tenho o livro de Caxambu do Sul e, da comunidade de cada um (dos alunos), faço entrevista com os idosos, primeiros moradores, filhos [...] Agora, da região, muito pouco, alguns livros eles trazem" (Maria). 
Embora, existam tentativas de trabalhar com o que está mais próximo, percebemos que a professora centra-se em alguns aspectos priorizados por uma concepção de história que dá pouca visibilidade e amplitude às questões sociais, políticas, econômicas, bem como as contradições existentes, nessas comunidades. Assim, torna-se necessário lembrar que uma região é composta por uma série de elementos envolvendo semelhanças e diferenças, assim como diferentes grupos étnicos que a compõem como afirma Cérri (1996), região é uma construção antes de tudo humana e, portanto submetida a uma determinada historicidade.

Como podemos observar, a professora Terezinha procura trabalhar o local e sua diversidade, mas the falta suporte teórico e metodológico para compreender suas especificidades e então desenvolver de forma consistente o estudo a partir da realidade mais próxima, com um olhar ampliado e contextualizado em outras temporalidades.

Para se localizar a gente usa o mapa, livro do município, livro da Mercedes, livros dicláticos, entrevistas com os pais, mas a maioria voltava em branco. Os pais não demonstravam interesse, vai um dia, volta em branco, vai outro dia, volta em branco. Isso desanima. Fazia também trabalhos em grupo, comparações com antigamente e hoje, produção de texto, a vida das mulheres, os costumes, o trabalho.

Pelas informações fornecidas pelas depoentes, verificou-se que as fontes de pesquisa usadas para preparar o trabalho para a sala de aula, dificilmente, ultrapassam os livros didáticos e um ou outro livro de âmbito local, como nos revela Sidonia:

() livro de Santa Catarina eu estou usando. Santa Catarina é o meu Estado. Não sei agora o autor do livro; um livrinho pequenininho. Têm outro, aquele Santa e Bela Catarina também. Qual é o outro que eu tenho? Acho que é viajando o mundo, me deixa vê! Essse aqui é mais Brasil, né? Os caminhos de Estudos Sociais. Tem os novos né, que sempre traz atualização; também tem pesquisas pro professor. Aí são assuntos assim mais para eles copiá. Então, isso é mais para eles fazerem sozinhos.

Neste depoimento, evidencia-se o uso quase que exclusivo de livros didáticos como guia para trabalhar com História no ensino Fundamental nos anos iniciais. 
Com relação à pesquisa, a mesma professora afirma que incentiva a sua realização e trabalha com ela em suas aulas. Porém, suá fala explicita que a intenção ou principal objetivo de suas aulas centra-se em outras áreas e temáticas, vejamos: " 0 que mais pesquisam? No caso é meio ambiente, Ibama, alguma coisa trabalha a vegetação. Agora estamos trabalhando o clima; também observar o clima, porque, assim, daí é junto com o meio ambiente; os rios também; eles pesquisam mais o que está dentro do conteúdo da $4^{\mathrm{a}}$ série".

Quanto à forma de trabalhar, na maioria das vezes é de forma fragmentada, ou seja, a abordagem dos conteúdos não acontece de maneira interdisciplinar como afirmou Sidonia "eu tô usando tudo separadinho: Estudos Sociais, Ciências... Teria que ser tudo junto, né? Mas, só que chega lá na 5 a série é tudo separadinho”. Na abordagem da professora destacamos a forma como ela explicita que o trabalho precisa ser de forma a unificar ou interdisciplinar os conteúdos e não de forma fragmentada. Como vemos a interdisciplinaridade é uma problemática que exige ainda muita discussão, tomada de decisão e vontade política para que aconteça nas escolas, pois como expressou a depoente, tem ficado mais nas pesquisas acadêmicas. Percebemos que ainda é preciso colocá-la em prática nas escolas do Ensino Fundamental.

Na concepção de Manique e Proença (1994), uma identidade constrói-se a partir da organização de vida de nossos antepassados. Fica então a pergunta: que identidade é essa, se as histórias de vida, do local não são priorizadas e, muitas vezes, substituídas por conteúdos ditos mais relevantes? Na relação com as falas das depoentes destaca-se o distanciamento entre o discurso e a prática da sala de aula no ensino do primeiro ao quarto ano referente à disciplina de história como evidenciamos nos depoimentos acima.

$\Lambda$ definição de conteúdos pela Proposta Curricular de Santa Catarina, prioriza a História próxima do aluno como temáticas a serem abordadas no ensino fundamental. Para que o ensino constitua-se como referencial crítico para o reencontro da integridade do humano no vivido. Permite ainda aos alunos conhecer diversos espaços (locais, regionais, nacionais e internacionais) e nas diversas temporalidades presentes no cotidiano.

Ao serem perguntadas sobre as implicações em trabalhar conforme a Proposta Curricular de Santa Catarina as professoras destacaram a dificuldade em colocá-la em prática devido à falta de conhecimento que possuem da mesma, 
como nos revelam estas falas "a Proposta Curricular eu acho que ela ajuda a fazer uma reflexão de como era trabalhada a História e nos mostra caminhos de como trabalhar. Acho que teria bastante coisa para a gente acrescentar, mas tem ajudado a fazer essa reflexão e trabalhar diferente a História" (Ivete). Ou ainda, conforme Terezinha "A Proposta até que está dentro do dia-a-dia, do que a gente deveria ensinar. Eu vejo assim. Vejo, ela como um instrumento que auxilia, mas a gente deixa de lado, até por não conhecer ela direito. Só que a gente não teve assim, um estudo aprofundado dentro de cada área, talvez seja por isso".

Outro aspecto que procuramos perceber foi como está estruturado e como é visto pelas professoras o Projeto Político Pedagógico das escolas. Elas destacaram que o Projeto Político Pedagógico existe em todas as unidades escolares as quais estão vinculadas sendo que foram construídos de forma coletiva e com a participação da comunidade escolar. Quanto à construção, é colocado à importância, mas quanto a sua concretização, percebemos que de fato, o que foi planejado, nem sempre acontece. Conforme o relato de Maria: "Foi em conjunto com a comunidade escolar. Olha o nosso tá mais no papel, a gente não consegue por em prática o quê planejou. Falta de tempo, muita correria, não se tem o tempo necessário".

Conforme Terezinha a execução do Projeto Político Pedagógico:

[...] não tá de acordo aqui na escola, porque está meio assim... O Projeto Político Pedagógico é uma coisa e o planejamento é outra. O Projeto Político e o planejamento deveriam estar juntos, dentro de projetos, sei lá. Coisas assim, como em outros colégios e aqui está esquecido. Cada um faz o que quer. Eu não acho certo. Falta garantir um espaço, um tempo para isso.

Vale fazer referência aqui, que há uma diferença entre os depoimentos da professora da rede pública estadual e as das escolas da rede municipal. De acordo com os dois depoimentos acima de professoras da rede estadual, colocam a existência do documento, porém, sua execução não ocorre, uma vez que, a escola está presa a um calendário escolar rígido e fechado no qual as reuniões pedagógicas e ou dias de estudo resumem-se em avisos e ou em preparação de atividades para datas comemorativas. Portanto, o Projeto Político Pedagógico se apresentou como mero cumprimento de uma exigência legal como desabafou 
a professora Sidonia, "Não é garantido um espaço. É. Não é garantido, não tem horário. Uma vez nós tínhamos isso, agora cortaram tudo. Não tem mais conselho de classe, dia de estudo. Os dias de estudo tão virando mais reuniões. A reunião pedagógica é só avisos".

No caso da rede municipal de ensino de Caxambu do Sul encontra-se uma abertura maior. Há possibilidades de estudo, embora o município não tenha uma proposta pedagógica definida, há tentativas de colocar em prática como nos diz a professora Ivete "Eu acho indispensável, né. Se não tem um projeto construído no coletivo, fica difícil. Acho indispensável para gente trabalhá, né?". Assim, a fala da professora Terezinha reforça o argumento da depoente anterior, referindo-se ao planejamento afirmou que este "é a base para uma escola funcionar. Sem um planejamento nada funciona. O Projeto Político Pedagógico é o planejamento da escola. Só que nem sempre é feito o que está nele. Às vezes, a gente demora em conseguir, leva anos, mas está planejado". Como podemos perceber, as depoentes entendem que o Projeto Político Pedagógico é o documento norteador da escola, mas, que, embora, a rede municipal de Caxambu do Sul ofereça uma abertura maior para encontros e estudos, ele ainda não é colocado totalmente em prática.

A partir dos questionamentos realizados e das falas das depoentes, entendemos que para se propor uma outra forma da escola pensar e desenvolver sua prática de forma coletiva há que se buscar caminhos que permitam um ensino mais voltado para a realidade próxima, contemplando o estudo do local e do regional contextualizando-o com as temáticas mais amplas.

Quando falamos do estudo de uma realidade mais próxima, nos referimos aos múltiplos aspectos que nos rodeiam: o meio socialmente construído, a ocupação e distribuição do espaço por homens, mulheres e crianças com seus costumes, tradições, trabalho, lazer, aliados aos problemas, contradições, conquistas entre outros elementos que precisam ser conhecidos e discutidos.

\section{Considerações Finais}

Para concluir, nada melhor do que dialogar com os escritos de Paulo Freire, que, com grande experiência e, na prática demonstrou que é possível buscar caminhos politicamente viáveis para o ensino, ao afirmar que: 
[...] o seu 'aqui' e o seu ' agora' são quase sempre o 'lá' do educando. Mesmo que o sonho do (a) educador (a) seja não somente tornar o seu 'aqui-agora', o seu saber acessível ao educando, mas ir mais além de seu 'aqui-agora' com ele ou compreender, feliz que o educando ultrapasse o seu 'aqui', para que este sonho se realize tem que partir do 'aqui' do educando e não do seu. No mínimo, tem de levar em consideração a existência do 'aqui' do educando e respeitá-lo. No fundo ninguém chega lá, partindo de lá, mas de certo aqui. Isto significa em última análise, que não é possível ao (a) educador (a) desconhecer, subestimar, negar os saberes de experiência feitos com que os educandos chegam à escola... (1994, p.59).

Este estudo propiciou reflexões sobre o ensino da história regional, assim como possibilitou conhecer um pouco mais a vida de algumas profissionais que atuam nos anos iniciais do Ensino Fundamental no município de Caxambu do Sul. Percebemos que, embora haja um planejamento mais direcionado para a realidade e a tentativa de ser trabalhado de forma interdisciplinar, ainda falta embasamento teórico metodológico e especialmente o conhecimento dos conteúdos específicos de história para os professores desta etapa da Educação Básica.

Com relação à temática, ainda há muito que se pesquisar, mas pelo que pudemos observar são vários os aspectos que dificultam o estudo das temáticas em questão, a deficiência na formação, as condições de vida, a fundamentação teórica e a falta de uma proposta definida entre outros elementos a serem considerados.

Ousamos apontar como sugestão uma possivel solução a inserção da Universidade, em parceria com os poderes público municipal e estadual, na divulgação dos artigos, monografias, dissertações e teses. Ou através do suporte teórico-metodológico na forma de oferecimento de cursos, oficinas... Como possíveis alternativas que facilmente podem ser pensadas, debatidas e posteriormente implementadas. Para tanto, basta um pouco de vontade política e diálogo entre as diferentes instituições.

\section{Referências}

AMADO, Janaína. História e Região: reconhecendo e construíndo epaços. In: SILVA, Marcos A da. República em Migalhas: História Regional e Local. São Paulo: Marco Zero, 1990.

CERRI, Luis Fernando. Regionalismo e Ensino de História. In: BITENCOURT, Circe Maria 
(org.) Anais do $2^{\circ}$ Encontro Perspectivas do Ensino de História. São Paulo: FEUSP, 1996.

CôGO, Anna Lucia. 0 perfil do profissional que ensina História de $1^{\mathrm{a}}$ a $4^{\mathrm{a}}$ série no eixo Ilhéus-Itabuna (1997-1998) In: BITENCOURT, Circe Maria (org.) Anais do $2^{\circ} \mathbb{E}$ Econtro Perspectivas do Ensino de História. Curitiba: Aos Quatro Ventos, 1999.

Depoimento de Gicela Gilioli Martiori.

Depoimento de Maria Cecchetti Santin.

Depoimento de Terezinha Laudete Biazus.

Depoimento de Sidonia Chiarello Giacomelli.

Depoimento de Ivete Gottardi da Silva.

Depoimento de Terezinha Miotto Mucelini.

Depoimento de Maria Cecchetti Santim.

FLORES, Maria Bernadete Ramos; SERPA, Élio Cantalício. A hermenêutica do vazio: fronteira, região e brasilidade na viagem do governador ao Oeste de SC. In: Projeto História 1.8 - Espaço e Cultura. São Paulo: Educ, 1999.

FREIRE, Paulo. A importância do ato de ler. 29 ed. São Paulo: Cortez, 1994.

FREIRE, Paulo. Pedagogia da Esperança. Rio de Janeiro: Paz e Terra, 3 ed. 1994.

FUCKNER, Cleusa Maria. 0 ensino de História nas séries iniciais. In: SCHMIDT, Maria Auxiliadora CAINELLI, Marlene Rosa (orgs.) Anais do $\mathbb{I I I} \mathbb{E n c o n t r o} \mathbb{P}$ erspectivas do Ensino de História. Curitiba: Aos Quatro Ventos, 1999, p. 174 a 178.

GALZZERANI, Maria Carolina Bovério. A produção de Saberes Históricos: saberes locais x saberes globais. In: Revista do Instituto Brasileiro de $\mathbb{E}$ dições $\mathbb{P} e d a g o ́-$ gicas - Área de Conhecimento: História. No 3, 2001, p.53-57.

História Local e Ensino de História. In: BITENCOURT, Circe Maria (org.). Anais do $2^{\circ}$ Encontro Perspectivas do Ensino de Hisória. São Paulo:LSP, 1996.

MACHADO, Ironita. A. P. O currículo de história. In: DIEHL, Astor Antonio (Org). O livro didático e o currículo de história em transição. Passo Fundo: EDIUPF, 1999.

MANIQUU, Antonio Pedro; PROENÇA, Maria Cândida. Didactica da história. Patrimônio e História Local. Lisboa: Texto Editora. 1994. 
MARCON, 'Telmo. História Regional: Uma experiência em construção. In: Anais do VI Encontro de Cientistas Sociais - Sobre'a Problemática Regional Aportes para o Futuro. Sedigraf: Ijuí-RS, 1996.

MARTINS, Paulo Henrique N. 0 Nordeste e a questão regional: os equívocos do debate. In: SIIVA, Marcos Antonio da. República em Migalhas: História Regional e Local. São Paulo: Marco Zero, 1990.

MAT"TOSO, José. A escrita da História. Lisboa: Editorial Estampa, 1988.

NÓVOA, Antonio (Org.). Profissão Professor. Porto - Portugal: Porto, 1991.

NOVOA, Antonio (Org.). Vidas de Professores. Porto - Portugal: Porto, 1992.

PAIM, Elison A . Considerações Acerca do Ensino História Regional e Local. Série Interdisciplinar, $n^{\circ}$ 52, Chapecó: Argos, 2003.

PARÂMETROS CURRICULARES NACIONAIS. Ensino de Quinta a Oitava Séries - Introdução. Brasília, 1998.

PORTELLI, Alessandro. 0 que faz a história oral diferente. In: Projeto História, n.14. São Paulo: EDUUC, 1997, p.25-39.

PRIORI, Ângelo. Desvendando as redes da memória local: ensino de história e vida cotidiana. In: SCHIMIDT, Maria Auxiliadora e CAINELLI, Marlene Rosa (org). Anais do III Encontro Perspectivas do Ensino de História. Curitiba: Aos Quatros Ventos, 1999.

PROPOSTA CURRICULAR DO ESTADO DE SANTA CATARINA, Florianópolis: IOESC, 1998, p. 165.

THOMPSON, Eduard P. A miséria da Teoria ou Um Planetário de Erros: crítica ao pensamento de Althusser. Rio de Janeiro: Zahar, 1981. 


\title{
The Regional History Teach in the First Years of Basic Education
}

\begin{abstract}
The reflections expressed in this article came from the research which teachers of initial grades primary education of municipal and state public schools in Caxambu do Sul - SC, trying to find how the history teaching happens, especially the local and regional themes. First we made some considerations about regional history teaching and express what we understand as region, as well. In a second moment we show the teachers that were interview and how they work with history in theirs classes.
\end{abstract}

Key-words: history teaching - regional history - basic education 